\title{
RAISON D'ÉTAT EM MONTAIGNE
}

\author{
Gilmar Henrique da Conceição* \\ gilmarhenriqueconceicao@hotmail.com
}

RESUMO Em "Do útil e do honesto" Montaigne indaga se, na defesa do Estado, haveria limites éticos para a ação do príncipe. O príncipe deve pautar-se pelo útil ou pelo honesto? Argumenta que o "devoir publique" éo limite da dedicação do súdito a um príncipe, o qual deve preservar a liberdade de julgamento. Ir além dos limites da consciência no serviço público é arriscar a confiança dos outros na veracidade de suas próprias palavras. Não há razão superior à razão de consciencia. Enquanto para Maquiavel o conceito de utilidade é fundamental, para Montaigne o útil não é o honesto. Ainda que a utilidade pública, mesmo que por uma "razão mais geral", obrigue à desonestidade, a moralidade deve vigorar no espaço público. A honestidade, no interior do espaço público, é uma força instituinte da sociedade política. Todavia, a pretensão à verdade e o cuidado com a "paix publique" são definitivamente distintos. Montaigne afirma a incompatibilidade entre a moral e a política, mas almeja um príncipe que não ignore o honesto.

Palavras-chave Montaigne, política, raison d'État.

ABSTRACT In "Of the useful and of the honest" Montaigne questions if, in the defense of the State, there shoud be any ethical limits to the action of the prince. Must the prince be guided by the useful or the honest? He argues that the "devoir publique" is the limit subjects have to respect in their dedication to the prince, preserving their freedom of judgment. In public affairs, going beyond the limits of conscience is risking the trust of others in the truth of

* Professor do Departamento de Filosofia da UNIOESTE-PR. Artigo recebido em 30 de junho de 2012 e aprovado em 12 de agosto de 2012.

KRITERION, Belo Horizonte, no 126, Dez./2012, p. 499-507 
one's words. There is no reason higher than consciousness. While, according to Machiavelli, the concept of utility is fundamental, Montaigne distingishes the useful from the honest. Even if the public utility (hence a "more general reason") may impose dishonesty, morality should prevail in the public space. Within the public space honesty is essential to institute the political society. However, to be truthful and to care about the "paix publique" are definitely different. Montaigne assumes the incompatibility between morality and politics, but not a prince who ignores the difference between the useful and the honest.

Keywords Montaigne, policy, raison d'État.

\section{Introdução}

Este artigo busca discutir algumas "opiniões" políticas de Montaigne acerca do dever público frente à razão "superior", no capítulo "Do útil e do honesto" (III, 1). ${ }^{1}$ Logo no início, Montaigne indaga: a quem a perfídia não deve ser detestável? Em seguida cita o caso de Tibério que preferia vingar-se dos inimigos abertamente, com as armas na mão, e não traiçoeiramente e às escondidas (III, 1, 790/5). Alguns parágrafos mais adiante, porém, Montaigne reconhece a utilidade daqueles que sacrificam a honra e a consciência para a salvação de seu país (III, 1, 791/6). Assim, o bem público requer pessoas que atraiçoem, que mintam e que massacrem, mas Montaigne repele para longe de si este tipo de serviço: “[...] prefiro falhar à causa que a mim!" (III, 1, 791/7). A seguir, pretendemos examinar a forma paradoxal com que Montaigne lida com aspectos da ideia de razão de Estado.

Como anuncia o título, a dicotomia entre o bem moral e o mal moral é estudado em "Do útil e do honesto". Deste capítulo interessa-nos, aqui, especialmente a discussão política do tema centrada na razão de Estado. Qual seja, é aceitável que não haja limites éticos na preservação do Estado? $\mathrm{Na}$ política, a melhor conduta é a útil ou a honesta? O poder político necessita de pessoas mentirosas e corruptas?

A discussão acerca do que pode ou não ser feito para preservar o Estado relaciona-se com o que veio a se chamar razão de Estado. Tal razão se coloca

1 As citações dos Ensaios seguem a tradução de Rosemary C. Abílio, pela Editora Martins Fontes. As referências a esta obra indicam, em números romanos, o livro, e em números arábicos, em sequência, o capítulo, a página da edição Villey-Saulnier (PUF) e a página da tradução da Editora Martins Fontes. 
acima de outras razões, visto que, de acordo com ela, cabe ao príncipe zelar acima de tudo pela segurança do próprio Estado e, no limite, o Estado deve sobreviver a qualquer custo. Assim, fazem parte do uso da razão de Estado: a violência, a desconfiança, a dissimulação, a corrupção, o engano, a perfídia e a injustiça. Portanto, de início Montaigne aceita a ideia de que o útil não está colado ao comportamento honesto, porque possui um valor prático. Todavia, parece que ele não distingue uma "boa razão de Estado" de uma "má razão de Estado", se forem alheias à ética: "[...] há alguma coisa ilícita até mesmo contra os inimigos [...]" e acrescenta: "[...] nem todas as coisas são lícitas a um homem de bem para servir a seu rei nem à causa geral e das leis" (III, 1, 802/24). Na ótica montaigniana, por razões de Estado, pequenas mentiras são permitidas, e as grandes, não o são?

Neste sentido de que forma o útil e o honesto acontecem na política? Esta pergunta é de fundamental importância porque nos leva a pensar a relação entre a moral e a política, que constitui um dos temas mais discutidos nos estudos que se interessam pela razão de Estado. Nas discussões iniciais da razão de Estado surgem diversas questões, tais como: $\mathrm{O}$ príncipe está acima da força coercitiva das leis? A força coercitiva da legalidade tem sempre a força diretiva da legitimidade? A política prescinde da moral? A perfídia, a conspiração e a crueldade acompanham necessariamente a ação política? Ou, numa linguagem mais contemporânea: o chamado terrorismo pode ser combatido sem o desrespeito aos direitos civis? É indispensável a existência de bases militares onde tais direitos não valem e onde a tortura é erigida em método de investigação?

\section{Breves traços do conceito de razão de estado}

O ponto de partida do conceito de razão de Estado se situa no limiar da Idade Moderna e é constituído pelas importantes e inspiradoras reflexões de Maquiavel, com que a ideia começa a emergir, em seus contornos mais gerais, mas não ainda a expressão "razão de Estado". Parece que Montaigne se atém especialmente a aspectos presentes em $O$ príncipe de Maquiavel. Sem dúvida, é possível descobrir, na história do pensamento político, numerosas antecipações parciais, às vezes bastante agudas, de tal teoria, mas é com Maquiavel que se registra um salto qualitativo como o começo de um novo tema a partir da citada obra. De modo que os princípios esboçados por Maquiavel, posteriormente, viriam a ser desenvolvidos sob a expressão razão de Estado. 
Por isso é com Maquiavel que Montaigne estabelece um tipo de diálogo sobre a questão do útil e do honesto, até mesmo na condição de conselheiro do príncipe, em especial nos capítulo "Do útil e do honesto" (III, 1), "Da presunção" (II, 17) e "Da experiência" (III, 13). O segundo momento especialmente significativo desta tradição está na reflexão e análise acerca da razão e dos interesses de Estado, em sua maioria, feitas por autores italianos e franceses, da segunda metade do século XVI e do século XVII ${ }^{2}$. Devemoslhes não só a introdução definitiva da expressão razão de Estado, com o significado que ainda hoje conserva, mas também novas determinações e aprofundamentos desse conceito e das suas implicações, e, particularmente, uma mais rigorosa distinção entre o interesse particular do príncipe e o interesse do Estado. Querendo resumir as teses da doutrina da razão de Estado numa definição tão sintética quanto possível e, consequentemente, genérica e abrangente, a ideia central que vem com esta tradição afirma que a segurança do Estado é uma exigência de tal importância que os governantes, para garantila, em caso de perigo para o Estado, são obrigados a violar normas jurídicas, morais, políticas e econômicas, que consideram imperativas em condições consideradas "normais".

Nos parágrafos iniciais em "Do útil e do honesto", Montaigne escreve que "não há nada inútil na natureza; nem mesmo a inutilidade" e acrescenta que "nosso ser está cimentado de qualidades doentias; a ambição, o ciúme, a inveja, a vingança, a superstição, o desespero alojam-se em nós com uma dominação tão natural [...]" (III, 1, 790/5-6). Portanto, o útil (e o desonesto) é próprio do modo de vida dos homens, mas, mesmo assim, condenável: ainda que se deixe a razão por uma razão "mais geral e poderosa; [...] certamente é uma infelicidade" (III, 1,799/19). Em outras palavras, afirma a incompatibilidade entre a moral e a política, mas almeja uma política que não ignore o honesto. A participação política de Montaigne ocorre num contexto de radicalização extrema; o que há não é apenas conflito, mas contestação, recusa das instituições. Nestes anos, a antiga fidelidade ao rei é substituída por uma "ideologia da razão de Estado", em que a violência é erigida em método de governar. A radicalização e a violência dos eventos trazem à tona um antagonismo entre o poder central e as províncias. Montaigne constata a disputa pelo poder entre as facções e vê que, na maioria das vezes, o assassinato político marca uma ruptura dos laços sociais e políticos, que degenera em caos. A sociedade está cindida em duas partes principais - o partido protestante e o 
partido católico -, e "[o] pensamento político fratura-se como o pensamento religioso, com os mesmos resultados mortíferos"3.

É problemático, porém, vincular Montaigne à raison d'État com o sentido atual mesmo criticamente, uma vez que este conceito apenas foi desenvolvido, como o entendemos atualmente, após a sua morte. Assim, se esta relação feita for direta ela é anacrônica. A rigor não é possível fazer de Montaigne um teórico da razão de Estado como a entendemos hoje, mas, ainda que historicamente, seu pensamento político deve ser compreendido como parte do debate que precedeu as teorias da razão de Estado.

Com este adendo, investigamos o sentido que Montaigne pensa aquilo que atualmente denominamos raison d'État. O questionamento se dá em torno da relação entre a conservação do Estado (o útil) e o honesto. Montaigne, aliás, escreve que quer "conservar": "Eu tinha apenas de conservar e durar, que são ações silenciosas e imperceptíveis. A inovação tem grande esplendor, mas é proibida nesta época em que somos pressionados e não temos senão de defender-nos das novidades" (III, 10, 1023/359). Essa ideia é retomada em outros capítulos: "Todas as grandes transformações abalam o Estado e o desorganizam" (III, 9, 958/259). O ensaísta, porém, não ignora que a "razão superior" - portanto, uma razão mais geral e poderosa em defesa do bem público ou da causa geral -, serve de paradigma da política de conservação. Todavia, "querer", "dever" e "consciência" definem a relação entre ética e política. Parece que Montaigne não distingue uma "boa razão de Estado" de uma "má razão de Estado", se forem alheias à ética. Compreende e prevê o perigo insidioso inerente ao sacrifício das virtudes morais e éticas em favor da política do "útil". Contraditoriamente, o desafio para a arte de governar impele inexoravelmente às tentativas de racionalizar a política. De seu lado, não renuncia a uma ética da responsabilidade e escreve contra tudo aquilo que é legitimado em nome de uma universal e poderosa razão. Neste debate, retoma Cícero:

A retomada desta terminologia e dos antônimos "útil" e "honesto" vem de Cícero, que, [...], não entendia essas duas palavras em seu estatuto epistemológico e moral de forma dicotômica. Na França, com as contribuições de Lucinge, Montaigne e Charron ao debate temos os sentidos, tanto homólogos, quanto diferentes para denunciar - é o caso de Montaigne - a ambiguidade histórica deste conceito, anunciando que é, sobretudo, uma posição contra a razão de estado. ${ }^{4}$ 
O ponto central para Montaigne é ressaltar a ilegitimidade do poder que busca violentar a consciência. A natureza engendra a sociedade para uma utilidade comum, sendo a sociedade, portanto, o resultado do "l'utile naturel". Parece que vislumbra as razões de Estado como ameaçadoras e conclui com a necessidade de se criar uma moral política contra a própria acepção da "raison d'État", que vem sendo construída. Diferente, portanto, da moralidade baseada exclusivamente na "razão superior", a moralidade se constrói sem nenhuma exigência de recursos alheios ao homem para formá-la. Além disso, diverge da ideia de que "razão de Estado, razões de consciência, e razão civil sejam um único conceito" ". Ao se posicionar negando categoricamente a equação de que a razão de Estado seja igual às razões de consciência e ao reconhecer que não há necessariamente harmonia entre política, ética e religião, também questiona se o Estado tem todas as razões e uma lógica que justifiquem afrontar a razão e a lógica comum. De modo geral, todos devem obedecer à lei sempre, mas o príncipe nem sempre. Ao se referir à necessidade de obedecer às leis apenas porque são leis, e não porque sejam justas, argumenta sobre o "fundamento místico de sua autoridade" (III, 13, 1072/433-434). Observe-se que escreve que devemos "disciplina e obediência" ao rei, mas não, necessariamente "estima", nem que nos furtemos a julgá-lo e de exprimir nosso descontentamento:

Devemos submissão e obediência a todos os reis igualmente, pois ela se refere a seu ofício; mas a estima, não mais que a afeição, só a devemos a seu valor. Condescendamos, pela ordem política, em pacientemente suportá-los indignos, calar sobre seus vícios, auxiliar com nossa consideração suas ações indistintamente, enquanto a autoridade deles necessitar de nosso apoio. Porém, terminado nosso comércio, não há razão para recusar à justiça e à nossa liberdade a expressão de nossos verdadeiros sentimentos [...] (I, 3, 16/21).

Montaigne não quer subversão para o Estado, mas reivindica o exercício da crítica como um serviço, visto que não há homens que mais necessitem de sinceras e livres advertências do que os príncipes. Alerta, contudo, que é preciso ter ouvidos duros para escutar um julgamento franco sem ofensa (III, 13, 1077/441). Entende que o poder político carece de "advertências" para que atenda ao bem comum e não se corrompa, porém esse exercício é muito perigoso para quem o faz, pois sempre paira a espada afiada de Dâmocles ${ }^{6}$, sus-

Cícero, em "Tusculanae disputationes" relata que Dâmocles, (Conselheiro da corte de Dionísio, o Velho), trocou de lugar com o rei, por uma noite, e sentiu na pele os riscos que podem sobrevir ao poder. A partir disso, "espada de Dâmocles" se tornou uma expressão que significa risco iminente que paira sobre o poder. 
pensa por um único fio de rabo de cavalo, sobre a cabeça dos que têm grande poder (como diz o relato do mito). Na maioria das vezes, os poderosos têm enorme medo de que o poder lhes seja tomado e confundem frequentemente "advertências" necessárias ao exercício do poder, com ameaça e sedição, dado que o poder está habituado à adulação com que os poderosos são revestidos, como uma segunda pele, em todas as épocas, tempos e lugares. Julga que a adulação é muito prejudicial aos príncipes ${ }^{7}$. Em vista disso, quando se fazem "advertências" aos poderosos, correm-se muitos riscos. Todavia, Montaigne reivindica para si o lugar de conselheiro do príncipe - "sem remuneração" (como ele sempre ressalta), para ser mais livre naquilo que tem para dizer - desde que pudesse dizer a verdade ao príncipe e criticar-lhe os costumes, mostrando o que pensam dele e não o que lhe asseguram os aduladores e os cortesãos ${ }^{8}$. Afirma que tem as credenciais de conselheiro do príncipe: "Eu teria tido lealdade, discernimento e liberdade suficiente para isso. Seria uma função sem nome; de outra forma perderia seu efeito e seu mérito" (III, 13, 1077/442). Tal ofício não seria remunerado, para não se corromper. Assim não ignora que tais serviços prestados a um soberano são rudes e arriscados, por isso exigem, além de muita afeição e franqueza, muita coragem. De forma que parece levar em consideração que é preciso um pressuposto básico para a política, que redunda em uma cadeia causal: não há bom governo (que ouve e que necessita de "advertências") sem sociedade ativa; não há sociedade ativa sem consciência política; não há consciência política sem o exercício de "sinceras e livres advertências" à autoridade do príncipe.

\section{Considerações finais}

Em "Do útil e do honesto", Montaigne argumenta que o príncipe, por razões de Estado, pode escolher o útil em detrimento do honesto. Justifica, porém o soberano que, em nome de sua consciência, recua diante de um crime proveitoso para a nação.

É preciso distinguir entre "submeter-se" às autoridades públicas e "escravizar-se": Montaigne requer lealdade ao príncipe, mas recusa prender-

7 "Não há coisa que envenene tanto os príncipes quanto a adulação, nem coisa pela qual os maus mais facilmente obtenham crédito em volta deles [...]" (II, 16, 619/429).

8 Em outro lugar Montaigne tece outra crítica observação acerca do posicionamento político dos cortesãos: "Um cortesão só pode ter direito e vontade de dizer e pensar favoravelmente sobre um senhor que, entre tantos milhares de súditos, escolheu-o para ser alimentado e engrandecido por sua mão. Este favor e proveito corrompem não sem alguma razão sua franqueza, e a ofuscam. Por isso habitualmente vê-se que a linguagem dessas pessoas é diferente de outra linguagem de qualquer posição, e pouco digna de fé em tal matéria" (I, 26, 155/ 232). 
se a ele de outra forma que não pelo dever público. Com isso procura delimitar a fronteira entre a liberdade pessoal e a obrigação social. Montaigne legitima a autoridade da lei à própria lei, e não tanto à autoridade do soberano ou do poder constituído.

No dilema entre obedecer a uma ordem odiosa do príncipe ou obedecer à própria consciência, Montaigne escolhe desobedecer ao príncipe. Mas escreve que o bem público requer aqueles que fazem tudo pelo bem público, inclusive atos criminosos. É essa sua liberdade: obedecer, porém estar disposto a desobedecer - e arcar com as consequências penosas disso - quando estiver em desacordo com sua consciência. $\mathrm{O}$ súdito não deve obediência às ambições pessoais do governante, mas à razão. De fato, nem todas as ações odiosas do príncipe são motivadas por razão de Estado, muitas vezes o são por questões privadas. $\mathrm{O}$ interesse privado é condenável quando busca manipular a coisa pública em benefício próprio. Em qualquer caso, é terrível a experiência daqueles que têm de optar entre a salvação pública e a preservação da honestidade. Entre o útil e o honesto Montaigne fica com o honesto: "Explicamos mal a honestidade e a beleza de uma ação por meio de sua utilidade; e concluímos mal ao estimar que todos estejam obrigados a ela [C] e que ela seja honesta para todos [B] se for útil [...]" (III, 1, 803/25).

$\mathrm{O}$ fundo no qual se destacam as ideias políticas de Montaigne sobre as relações entre o príncipe e os outros homens é o da atitude moral da compaixão diante das guerras, torturas e perseguições. Na interpretação de Starobinski ${ }^{9}$, tal atitude fica aquém de toda teoria política. Todavia, o príncipe não pode regrar suas ações somente pela opinião comum, porque pode haver casos em que precisará contrariá-la, como remédio extremo e desesperado que requer a "prostituição da consciência" (III, 1, 799/18). Nestes casos, o príncipe fez o que precisava ser feito, "[...] mas se o fez sem lamentar, se não lhe pesou fazê-lo, é sinal de que sua consciência está em maus termos" (III, 1, 799/19).

Conforme Montaigne, como a concórdia é o mais precioso de todos os bens, é preciso obedecer à ordem herdada por uma razão maior: a da paz pública e da sobrevivência da comunidade. Ele não identifica, porém, a autoridade "superior" com aquela que o próprio príncipe se atribui. Por isso, nem todas as coisas são lícitas a um homem de bem para servir a seu rei nem à causa geral e das leis (III, 1, 802/24). 


\section{Referências bibliográficas}

AMES, José Luiz. "Uma teoria do conflito: Maquiavel e Marx". In: Educere et educare, v.3, n. 6, 2008, p. 55.

BERNS, Thomas. "La politique de l'amitié chez Montaigne". Actes du Colloque International tenu à University of Chicago (Paris) les 29 et 30 avril 2006. Paris: Éditions Champions, 2006.

BOBBIO, N. Dicionário de Política. Tradução de Carmen C. Varriale, Gaetano Lo Mônaco, João Ferreira,Luís Guerreiro Pinto Cacais e Renzo Dini. Brasília: Editora Universidade de Brasília, 1986.

LA BOÉTIE, Discurso da servidão voluntária. Tradução de Laymert Garcia dos Santos. São Paulo: Brasiliense, 1999.

CÍCERO, Marco Túlio. Dos Deveres (De Officiis). Tradução de Angélica Chiapeta. São Paulo: Martins Fontes, 1999. Coleção Textos Filosóficos, 2000.

MAQUIAVEL. O Príncipe. Tradução de Lívio Xavier. São Paulo: Abril Cultural, 1973.

MONTAIGNE. Os Ensaios. Tradução de Rosemary Costhek Abílio. São Paulo: Martins Fontes, 2000.

PANICHI, Nicola. "Au-delà de la vertu 'innocente': Montaigne et les théoriciens de la raison d'État". In : Actes du Colloque International tenu à University of Chicago (Paris) les 29 et 30 avril 2006. Paris: Éditions Champions, 2006.

STAROBINSKI, Jean. Montaigne em movimento. Tradução de Maria Lúcia Machado. São Paulo: Cia da Letras, 1993

TOURNON, ANDRÉ. Montaigne. Tradução de Edson Querubini. São Paulo: Discurso Editorial, 2004

TOURNON, ANDRÉ. "Justice and the law: on the reverse side of de Essays". In: The Cambridge Companion to Montaigne. Cambridge: Cambridge University Press, 2005. 